\title{
ГИДРОГЕНИЗАЦИЯ И КОНВЕРСИЯ ГОРЮЧЕГО СЛАНЦА ЧАГАНСКОГО МЕСТОРОЖДЕНИЯ
}

В горючем сланце Чаганского месторождения Оренбургской области, несмотря на высокое содержание серы $(8,5 \%)$, относительно много (до $60 \%$ ) органического вещества (ОВ). Геологическая характеристика чаганского горючего сланца, а также общая характеристика его OB и данные изучения битумондов приведены в ['].

Целью настоящей работы было исследование структуры ОВ чаганского сланца деструктивными методами - гидрогенизацией и конверсией в автоклаве. Для сравнения проводили также полукоксование. Исходным сырьем служил измельченный, без предварительной обработки сланец со следующими показателями, вес. $\%: W^{a}-2,9 ; A^{c}-$ 35,$7 ; \mathrm{CO}_{2 \text { (мин) }}^{\text {c }}-7,6$; условная органическая масса $-56,7$. Элементный состав, вес. \%: C - 62,5; H $\mathrm{H} / \mathrm{C}-1,6$. Выход битумоидов на ОВ: A $-1,1$; C $-0,8$. Все опыты проводили по ранее описанной медодике [2]. Полученные смолы разделяли на группы соединений препаративной тонқослойной хроматографией (ТСX) [3]. Суммарные смолы и фракции с тонкого слоя анализировали газохроматографнчески на приборе «Хром-4». Фенолы выделяли из смол $10 \%$-ным раствором щелочи. ИК-спектры смол снимали на спектрофотометре UR-10, a ${ }^{1} \mathrm{H}-9 M \mathrm{M}$-спектры - на аппарате фирмы «Tesla». Серу определяли по модифицированному колбовому методу $\left[{ }^{4}\right]$. Смолу гидрогенизации дополнительно разделяли методом сухой колонки [5]. Фракционный состав сланцевых смол конверсии, гидрогенизации и полукоксования определяли газохроматографической имитированной дистилляцией [ $\left.{ }^{6}\right]$.

Проведены следующие автоклавные опыты: каталитическая гидрогенизация, термическое растворение и конверсия с водой, с водным раствором щелочи и с щелочным раствором метанола. В автоклав помещали 100 г сланца и 400 мл растворителя - бензола в опытах гидрогенизации и термического растворения, воду и $5 \%$-ный водный (метанольный) раствор гидроокиси натрия при конверсии. Для каталитической гидрогенизации сланец пропитывали раствором молибдата аммония из расчета $1 \%$ Мо на ОВ сланца. При гидрогенизации первоначальное давление водорода не превышало 9,8 МПа. Известно [ $\left.{ }^{7,8}\right]$, что при критической температуре и высоком давлении вода одновременно действует как восстановитель и как окислитель. В целях изучения чисто термического воздействия на сланец его растворяли в бензоле без катализатора и избыточного водорода. Все опыты проводили при температуре $370^{\circ} \mathrm{C}$ в течение 3 ч, за исключением двух опытов гидрогенизации, когда продолжительность процесса увеличивали до 50 ч, а температуру понижали до $300^{\circ}$. Полукоксование сланца проводили по ГОСТу 3168-66.

При сравнении выходов смол термической деструкции (табл. 1) видно, что выход смолы при гидрогенизации выше $(55 \%)$, чем при 
Выход и характеристика смол, полученных при термической деструкции горючего сланца Чаганского месторождения $\left(370^{\circ}, 3\right.$ ч)

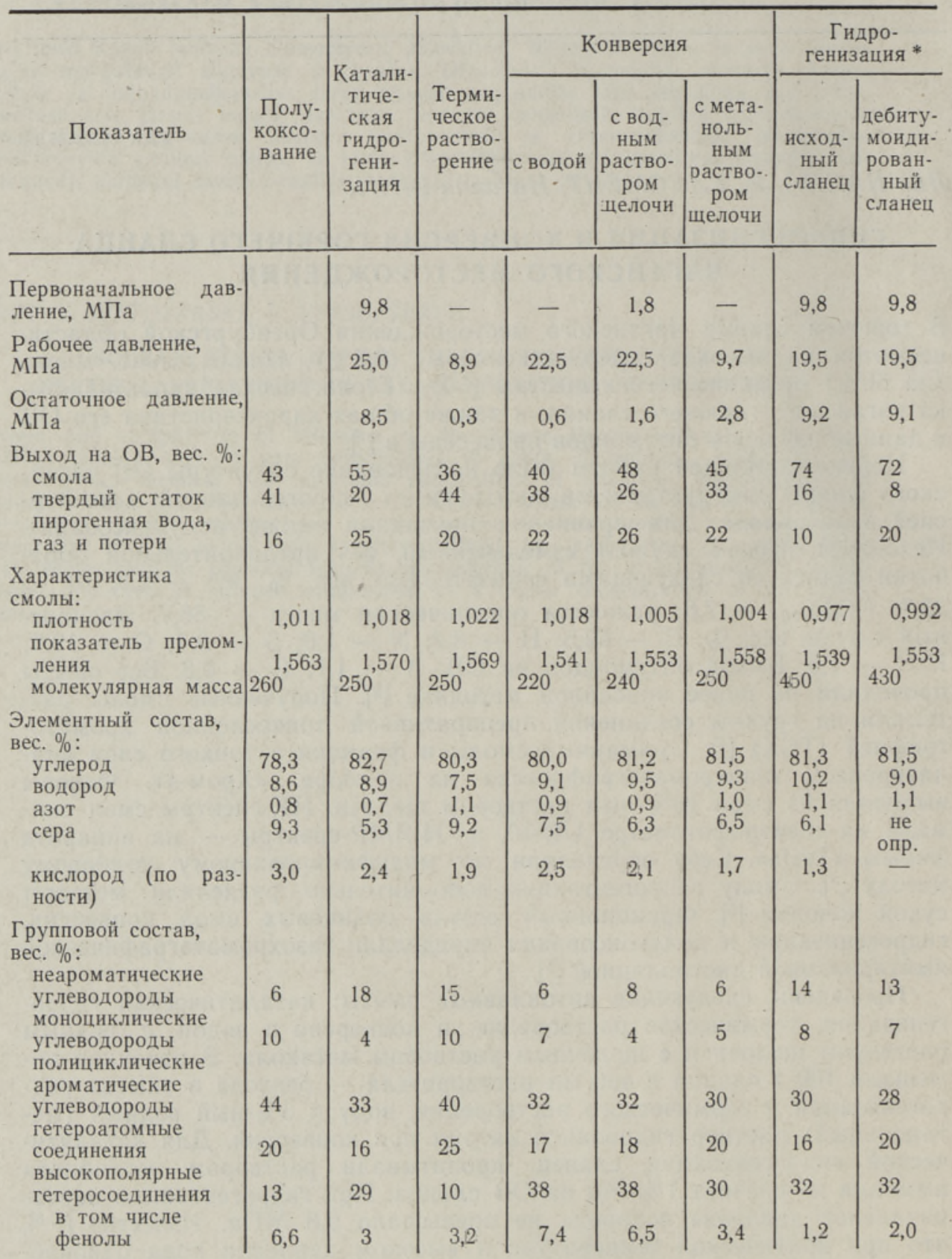

* Температура $300^{\circ}$, время 50 ч.

полукоксовании $(43 \%)$, а при термическом растворении ниже $(36 \%)$. Выход смолы увеличивается до $74 \%$ при удлинении времени гидрогенизации до 50 ч и снижении температуры до $300^{\circ}$. Для сравнения выходов смолы длительную гидрогенизацию провели как с исходным, так и с дебитумоидированным сланцем. Данные показывают, что предварительная обработка сланца не оказывает существенного влияния ни на 
выход, ни на состав полученной смолы. Выход смолы при конверсии существенно не отличается от ее выхода при полукоксовании, но увеличивается с прибавлением щелочи. Состав газов конверсии и термического растворения отличается от состава газа полукоксования, где много $\mathrm{H}_{2} \mathrm{~S}(56,5 \%)$ и мало $\mathrm{CO}$ и $\mathrm{CO}_{2}$ (3,2 и $7,8 \%$ соответственно). Газы конверсии и гидротенизации содержат меньше сероводорода $(14-22 \%)$, , больше двуокиси углерода $(17-42 \%)$, а при конверсии в щелочном растворе образуется много водорода (до $44 \%$ ). Это указывает на различный механизм деструкции в автоклаве и алюминиевой реторте. В элементном составе смол деструкции нет резких различий. При гидрогенизации и конверсии намечается некоторое снижение серы в смоле: при полукоксовании - 9,3\%; при гидрогенизации - 5,3\%; при конверсии с водой - 7,5\%, с раствором щелочи - до 6,5\%. Сера распределяется между группами смолы неодинаково (табл. 2). Так, в неароматических углеводородах смол деструкции серы совсем нет, зато во фракциях ароматических (полициклических) углеводородов на ее долю приходится около $60 \%$ от общей серы. Высокополярные гетеросоединения, не поддающиеся хроматографическому разделению, содержат $27 \%$ серы, фракция кислородсодержащих соединений около $11 \%$. В смоле полукоксования [9] во фракциях ароматических соединений присутствует примерно $70 \%$ от общей серы, остальные $30 \%$ приходятся на гетероатомные соединения. По молекулярному и удельному весу, а также по показателю преломления автоклавные смолы мало отличаются как между собой, так и от смолы полукоксования. Естественно, что смолы, полученные при более низкой температуре и длительной гидрогенизации, имеют намного выше молекулярный вес (450), чем смола полукоксования (250), поскольку деструкция сланца происходит в этих условиях менее глубоко. Вследствие низкой температуры и избыточного количества водорода часть ароматических структур гидрируется в циклогексановые, обусловливая понижение удельного веса и показателя рефракции полученных гидрогенизатов.

Для группового состава полученных смол характерно довольно высокое содержание ароматических углеводородов (до $40 \%$ ), а также наличие высококонденсированных полициклических гетероатомных соединений с высоким содержанием серы, не поддающихся разделению способом ТСХ и остающихся на старте $(25-28 \%)$. Кислородные соеди-

Распределение серы по фракциям гидрогенизата чаганского сланца

\begin{tabular}{|c|c|c|}
\hline Группа & 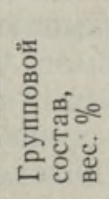 & 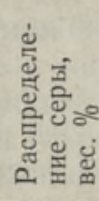 \\
\hline $\begin{array}{l}\text { Неароматические углево- } \\
\text { дороды }\end{array}$ & 18 & \\
\hline $\begin{array}{l}\text { Моноциклические арома- } \\
\text { тические углеводороды }\end{array}$ & 4 & 4 \\
\hline $\begin{array}{l}\text { Полициклические арома- } \\
\text { тические углеводороды }\end{array}$ & 33 & 58 \\
\hline $\begin{array}{l}\text { Гетероатомные соедине- } \\
\text { ния }\end{array}$ & 16 & 11 \\
\hline $\begin{array}{l}\text { Высокополярные гетеро- } \\
\text { соединения }\end{array}$ & 29 & 27 \\
\hline
\end{tabular}

Коэффициенты нечетности алканов $\mathrm{C}_{10}-\mathrm{C}_{22}$, полученных в процессе термической деструкции чаганского сланца

\begin{tabular}{l|l}
\hline \multicolumn{1}{c|}{ Способ деструкции } & КН \\
\hline & \\
Полукоксование & 1,10 \\
Конверсия с водой & 1,13 \\
Конверсия с водным раствором & \\
щелочи & 1,30 \\
Конверсия с метанольным раст- & \\
вором щелочи & 1,12 \\
Термическое растворение & 1,22 \\
Каталитическая гидрогенизация & 1,19 \\
Гидрогенизация дебитумоиди- \\
рованного сланца
\end{tabular}




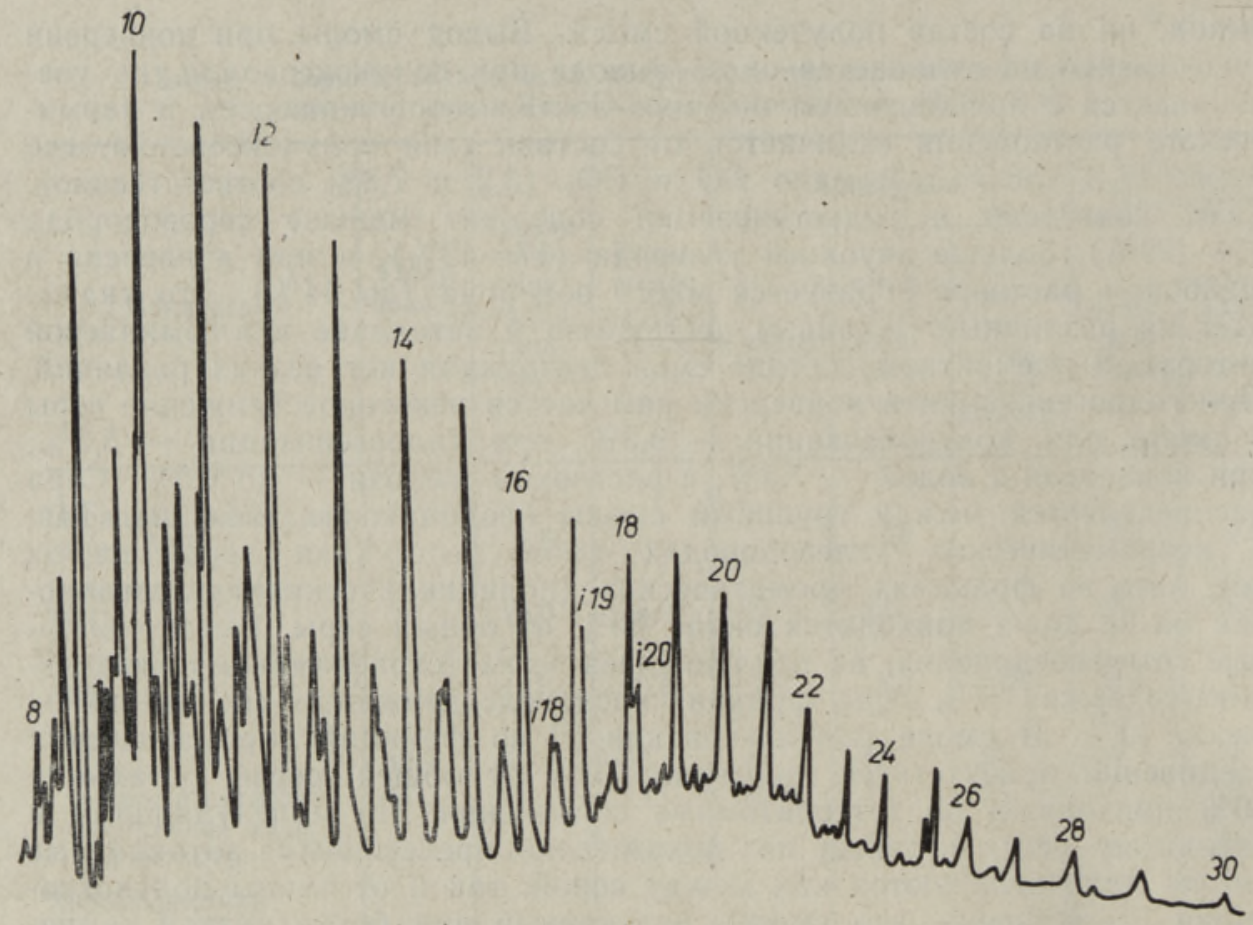

Рис. 1. Хроматограмма фракции алифатических углеводородов смолы гидрогенизации, разделенная в сухой колонке. Цифры 8-30 - число атомов углерода в молекуле н-алкана, $i 18-i 20$ - изопренондные структуры. Колонка: $4 \%$ Е 301 на хроматоне N-AW-DMCS, 3,6 м $\times 3$ мм.

нения составляют от 16 до $25 \%$ от смолы. Количество фенолов в смоле зависит от конкретных условий переработки: при гидрогенизаций их образуется $2-3 \%$, при полукоксовании и конверсии - до $7 \%$. Алифатические углеводороды составляют от 6 до $18 \%$ от всего количества смолы, причем при гидрогенизации их образуется больше, чем при конверсии.

Среди алифатических углеводородов, как и обычно в смолах, полученных при гидрогенизации сапропелитов, основными компонентами являются лишь нормальные и разветвленные алканы, а при конверсии в смолах присутствуют в следовых количествах и $\boldsymbol{H}$-алкены. Идентифицированы алканы, в молекуле которых насчитывается от 8 до 30 атомов углерода. Присутствуют и изопреноидные структуры от $i \mathrm{C}_{18}$ до $i \mathrm{C}_{20}$ (рис. 1). Хроматограммы алканов показывают, что в смолах превалируют гомологи с нечетным числом атомов углерода в молекуле. Отношения «нечетных» гомологов к «четным» (коэффициент нечетности - КН) рассчитаны по формуле из $\left[{ }^{10}\right]$ и приведены в табл. 3. Алканы $\mathrm{C}_{10}-\mathrm{C}_{12}$ смолы полукоксовапия имеют низкое, хотя и превышающее единицу, значение КН. В целом повышенные по сравнению с ним значения КН алканов смолы гидрогенизации и конверсии указывают на то, что $\beta$-отщепление при этих способах деструкции происходит в меньшей мере, чем при полукоксовании, а также на то, что ОВ в ходе диагенеза не подвергалось глубоким вторичным процессам превращения.

По индивидуальному составу ароматических групп и гетероатомных соединений автоклавные смолы мало отличаются от смол полукоксования. Моноциклические ароматические углеводороды сконцентрированы в низкокипящей фракции смолы, что характерно для всех смол, 


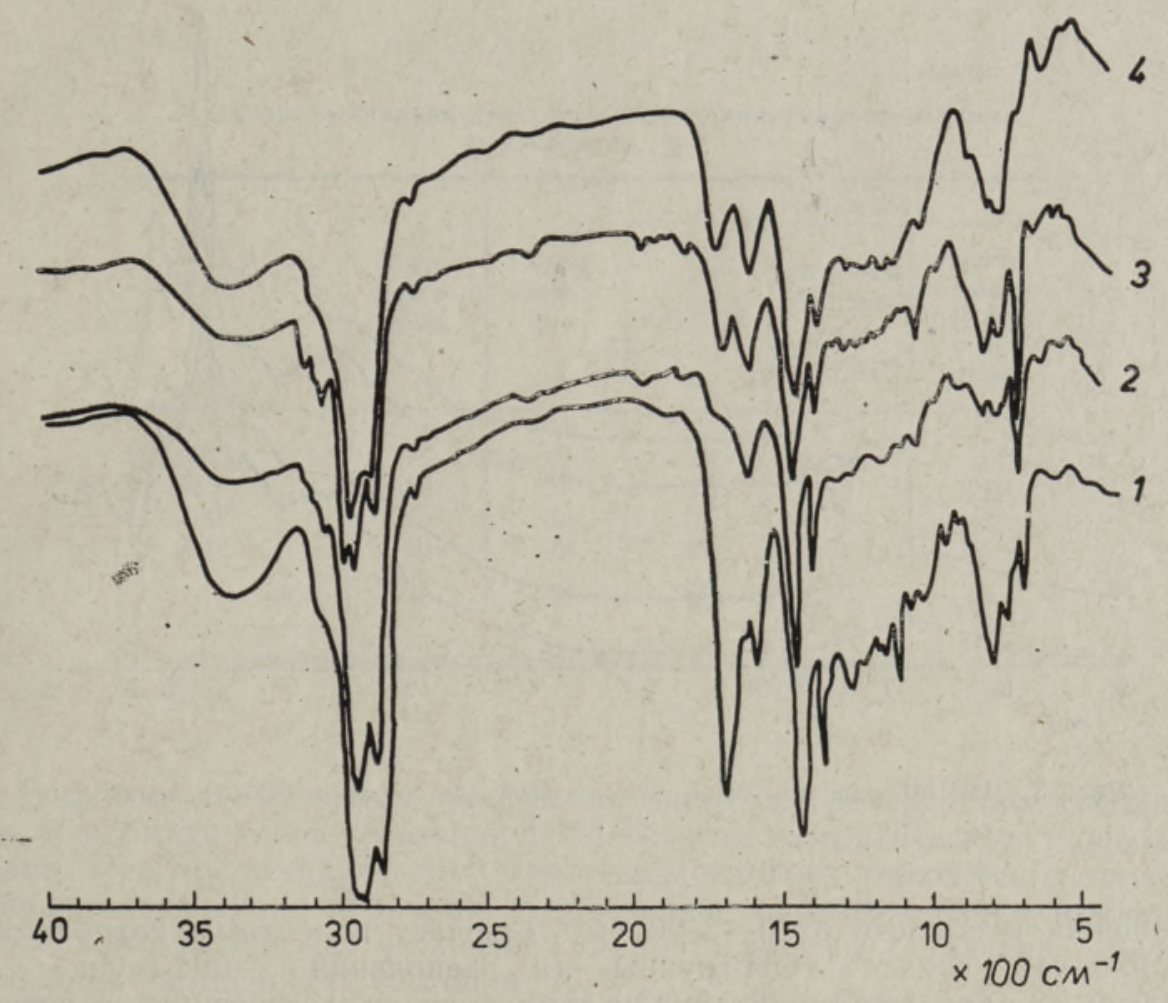

Рис, 2. ИК-спектры смол термической деструкции: 1 - полукоксование, $2-$ гидрогенизация, 3 - термическое растворение, $4-$ конверсия.

получаемых из сернистых сланцев. Фракции моноциклических соединений смол гидрогенизации и конверсии в основном состоят из гомологического ряда алкилбензолов (н-алкилы $\left.\mathrm{C}_{4}-\mathrm{C}_{12}\right)$; в низкокипящей части смол обнаружены также бензол и толуол. Полициклические ароматические соединения представлены главным образом углеводородами нафталинового ряда. Идентифицированы нафталин, 1- и 2-метилнафталин, дифенил, диметилнафталины и аценафтен. Концентрация нафталина в гидрогенизатах и в смоле конверсии несколько выше, чем в смоле полукоксования. Если в последней 1- и 2-метилнафталины присутствуют почти в одинаковых количествах, то в смолах гидрогенизации и конверсии концентрация 2-метилнафталина выше. Присутствие во фракции полициклических ароматических соединений до $55 \%$ от общей серы затрудняет разделение и хроматографический анализ этой фракции.

Кислородсодержащая фракция представлена в основном $н$-алканами, но их состав меняется в зависимости от метода термической деструкции. Если в низкокипящей части смолы полукоксования доминируют прямоцепочечные 2-алканоны (метилкетоны), то начиная с молекулы $\mathrm{C}_{15}$ преобладают алканоны с карбонильной группой в центральном положении. В смолах конверсии встречаются н-алканоны от $\mathrm{C}_{8}$ до $\mathrm{C}_{22}$, как и в смоле конверсии кукерсита [7]. Количество н-алканонов здесь почти соответствует количеству $н$-алканов. В процессе гидрогенизации алканонов образуется мало. Выделенные из смол гидрогенизации и конверсии фенолы представлены одноядерными соединениями: оксибензолами, метилоксибензолами и диметилоксибензолами. Нафтол же присутствует лишь в следовых количествах.

Изучение ИК-спектров (рис. 2) показало, что широкая полоса по- 


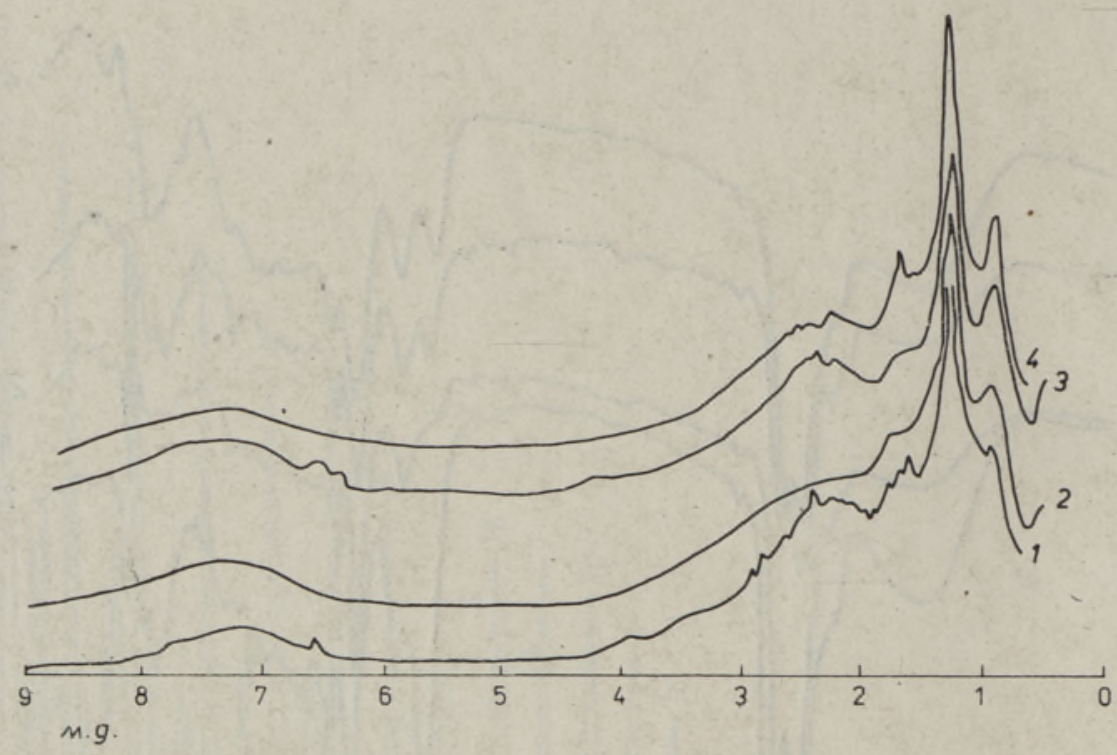

Рис. 3. ' на рис. 2.

глощения в области $3200-3500 \mathrm{~cm}^{-1}$ отвечает валентным колебаниям водородной связи -ОН-группы (в фенольной -OH-группе $\left.3400 \mathrm{~cm}^{-1}\right)$, при гидрогенизации и термическом растворении ее интенсивность намного меньше. Максимум-поглощения при 3030 и $760 \mathrm{~cm}^{-1}$ отвечает валентному колебанию ароматических - $\mathrm{CH}$-групп, которые могут находиться и в фенольном кольце. Полоса поглощения при $1600 \mathrm{~cm}^{-1}$ обусловлена присутствием бензольных колец. Деформационное колебание алифатических $-\mathrm{CH}_{2}$ и $-\mathrm{CH}_{3}$-групп выражено поглощением при 1400 и $1380 \mathrm{~cm}^{-1}$. Области поглощения 1710 и $1730 \mathrm{~cm}^{-1}$ соответствуют колебаниям карбоксильных и карбонильных групп, на присутствие связей $\mathrm{C}-\mathrm{O}, \mathrm{C}=\mathrm{S}, \mathrm{S}=\mathrm{O}, \mathrm{C}-\mathrm{N}$ гетероэлементов указывают полосы поглощения в области $1100-1300 \mathrm{~cm}^{-1}$.

Для установления строения соединений, присутствующих в смолах термической деструкции, были сняты также ${ }^{1} \mathrm{H}$-ЯМР-спектры (рис. 3). На спектрах четко прослеживаются сигналы алифатических протонов. Сигналы при 0,8-1,0 м. д. соответствуют метильным концевым группам, при 1,2-1,5 м.д. - длинным метиленовым цепям, начиная с метиленовой группы, расположенной в $\gamma$-положении. Протоны метильной группы в $\beta$-и $\alpha$-полложениях, связанные с ароматическим ядром, вызывают сигналы в областях $1,5-1,65$ и $1,88-2,37$ м. д. соответственно. Широкий сигнал в интервале $6,35-8$ м. д. принадлежит протонам, связанным с ароматическими ядрами. Ароматические протоны гетероциклических систем проявляются в той же области. Хотя данные 'Н-ЯМР-спектров указывают на ароматический характер смолы, ароматических протонов в ней мало, большинство атомов водорода находится в метиловых группах, связанных с ароматическим ядром, или в гидридных нафтено-ароматических и бензотиофановых структурах.

Данные имитированной дистилляции (табл. 4) показывают, что в смоле полукоксования выкипающая часть составляет $53 \%$, тогда как при гидрогенизации и конверсии она доходит до $58 \%$, а в щелочном растворе метанола достигает $60 \%$. Смолы гидрогенизации и конверсии содержат больше соединений, выкипающих до $200^{\circ}(12-16 \%)$, чем смола полукоксования $(5 \%)$. 


\section{Таблица 4}

Пределы выкипания смол полукоксования, гидрогенизации и конверсии, \% *

\begin{tabular}{|c|c|c|c|c|c|}
\hline \multirow[b]{2}{*}{$\begin{array}{c}\text { Температура, } \\
{ }^{\circ} \mathrm{C}\end{array}$} & \multirow[b]{2}{*}{$\begin{array}{l}\text { Полу- } \\
\text { коксо- } \\
\text { вание }\end{array}$} & \multirow[b]{2}{*}{$\begin{array}{l}\text { Гидро- } \\
\text { гениза- } \\
\text { щия }\end{array}$} & \multicolumn{3}{|c|}{ Конверсия } \\
\hline & & & с водой & $\begin{array}{c}\text { с водным } \\
\text { раство- } \\
\text { ром } \\
\text { щелочи }\end{array}$ & $\begin{array}{c}\text { с мета- } \\
\text { нольным } \\
\text { раство- } \\
\text { ром } \\
\text { щелочи }\end{array}$ \\
\hline $\begin{array}{cc}\text { До } & 200^{\circ} \\
, & 250^{\circ} \\
\Rightarrow & 300^{\circ} \\
", & 350^{\circ}\end{array}$ & $\begin{array}{r}5 \\
16 \\
25 \\
33\end{array}$ & $\begin{array}{l}12 \\
27 \\
38 \\
48\end{array}$ & $\begin{array}{l}12 \\
22 \\
32 \\
47\end{array}$ & $\begin{array}{r}8 \\
19 \\
29 \\
41\end{array}$ & $\begin{array}{l}16 \\
28 \\
42 \\
50\end{array}$ \\
\hline Bcerc & 53 & 58 & 56 & 58 & 60 \\
\hline
\end{tabular}

* Газохроматографическую имитированную дистилляцию провел $\mathrm{X}$. Луйк.

В смолах термической деструкции много серосодержащих соединений и ароматических углеводородов, меньше алифатических углеводородов. Предположение о том, что происхождение горючего сланца в основном связано с морскими организмами, подтверждает и изучение изотопного состава ОВ чаганского сланца: для него характерна значительная обогащенность изотопом ${ }^{13} \mathrm{C}\left[{ }^{11}\right]$.

По выходу смолы (в среднем $50 \%$ на ОВ) чаганские сланцы заметно отличаются от других высокосернистых сланцев. Это, очевидно, обусловлено высоким содержанием ОВ в исходном материале - чем больше ОВ в сланце, тем выше и выход смолы из ОВ. Особого внимания заслуживают высокий выход смолы $(70 \%)$ и ее особый состав прн низкотемпературной гидрогенизации $\left(300^{\circ}\right)$.

\section{Л И ТЕР А Т У Р А}

1. Клесмент И., Побуль Л., Куузик М. Характеристика битумоидов горючего сланца Чаганского месторождения Оренбургской области. - Изв. АН ЭССР. Хим., 1981, 30, № 3, 187-193.

2. Наппа Л., Клесмент И., Винк Н., Кайлас К. Исследование деструктивной гидрогенизацией рабдописситового угля Липовецкого месторождения. - Изв. АН ЭССР. Хим., 1981,30 , № 1, 10-16.

3. Klesment, I. Application of chromatographic methods in biogeochemical investigations. - J. Chromatogr., 1974, 91, № 2, 705-713.

4. Побуль Л. Дополнения к колбовому методу Шёнигера и его использование для определения серы в органических соединениях. - Изв. АН ЭССР. Хим., 1981, 30, № 4, 302-304.

5. Кивиряхк С., Клесмент И. Хроматография в сухой колонке. Состав смолы полукоксовання липтобиолита. - Изв. АН ЭССР. Хим., 1981, 30, № 3, 18С-186.

6. Луйк X. Использование симулированной дистилляции для определения фракционного состава сланщевых смол. - В кн.: Тезисы докл. III респ. конф. молодых ученых химиков. Таллин, 1979, 212.

7. Klesment, I., Nappa, L. Investigation of the structure of Estonian oil shale kukersite by conversion in aqueous suspension. - Fuel, 1980, 59, 117-122.

8. Клесмент Н. Р., Наппа Л. А., Уров К. Э. Низкотемпературная гидрогенизащия и конверсия горючих сланцев как методы исследования их структуры и получения жидких продуктов. - Хим. тверд. топл., 1980, № 6, 108-115.

9. Салусте С., Клесмент И. Анализ смолы лабораторного полукоксования горючего сланца Чаганского месторождения. - Изв. АН ЭССР. Хим., 1981, 30, № 4, $249-257$.

10. Bray, E. E., Evans, E. D. Distribution of $n$-paraffins as a due to recognition of source beds. - Geochim. et Cosmochim. Acta, 1961, 22, N 1, 2-9. 
11. Муеллер С., Клесмент И., Пуннинг Я.-М., Вайкмяэ Р. Изотопный состав углерода некоторых сапропелитов как показатель их формирования. - Изв. АН ЭССР. Хим., 1981, 30, № 2, 84-90.

Ннститут химии

Академии наук Эстонской ССР
Поступила в редакцию

18/II 1983

\section{Lia NAPPA, I. KLESMENT, Natalja VINK}

\section{TŠAGANSKI LEIUKOHA POLEVKIVI HUDROGEENIMINE JA KONVERTEERIMINE}

Tšaganski leiukoha põlevkivis on 'kõrgest väävlisisaldusest $(8,5 \%)$ hoolimata suhteliselt palju $(60 \%)$ orgaanilist ainet, mille struktuuri on uuritud destruktiivsete meetoditega - hüdrogeenimise, konverteerimise ja utmisega. Olisaagis oli keskmiselt $50 \%$, mis ületab analoogsete väävlirikaste põlevkivide saagise. Suurim õlisaagis saadi katalüütilisel hüdrogeenimisel ja madalatemperatuurilisel pikaajalisel hüdrogeenimisel. Saadud õlidele on iseloomulik aromaatsete süsivesinike ja väävlit sisaldavate ühendite rohkus, alifaatseid ühendeid esineb vähem.

\section{Lia NAPPA, I. KLESMENT, Natalya VINK}

\section{HYDROGENATION AND CONVERSION OF CHAGANSK OIL SHALE}

In spite of its high sulphur content - $8.5 \%$ - Chagansk oil shale reveals a relatively high organic content $(60 \%)$. The structure of organic matter was investigated by thermal destructive methods - hydrogenation, conversion, and semi-coking. The oil yields obtained by decomposition processes were $50 \%$ on the average which was higher than the yields from other analogical sulphur-rich oil shales. The highest oil yields were obtained by catalytic and low temperature $(50 \mathrm{~h})$ hydrogenation. The liquids were characterized by a high content of aromatic and heteroatomic compounds containing sulphur, since the content of aliphatic compounds was low. 